Article

\title{
Parasympathetic Nerve Functions in Type 2 Diabetes Mellitus: Relation to Glycemic Status and Duration of Diabetes
}

\begin{abstract}
Alam MK ${ }^{1}$, Begum N ${ }^{2}$, Begum $S^{3}$
Background: Cardiovascular autonomic dysfunction is associated with higher mortality and is a common health problem observed in diabetic patients. Early detection of autonomic dysfunction in diabetic patient is important for prevention of this complication. Objectives: The study has been designed to observe the parasympathetic nerve function status in type 2 diabetic subjects in order to assess the relationship between glycemic status and duration of diabetes and the parasympathetic nerve function. Study Design: This cross section study was carried out in the Department of Physiology, Bangabhandhu Sheikh Mujib Medical University, Dhaka, Bangladesh. Forty seven type 2 diabetic subjects were included in two groups. Group B consisted of 25 recently diagnosed diabetic subjects aged 40-68 years and group $C$ consisted of 22 subjects having duration of diabetes for $10-20$ years. Twenty five (25) age and BMI matched healthy subjects were included in group A (non diabetic) for control. Methods: Parasympathetic nerve functions were assessed by three simple non invasive cardiovascular reflex tests. These were Valsalva maneuver, Heart rate variation (HRV) to deep breathing, HRV to standing up. Glycemic status was assessed by serum glycosylated hemoglobin $\left(\mathrm{HbA}_{1 \mathrm{C}}\right)$ and fasting plasma glucose (FPG). Data were analyzed by 't' test, Pearson's correlation coefficient. Results: Valsalva ratio was significantly lower in group $C$ than that of group A but no significant difference was observed between group B \& A and also between B and C. HRV in deep breathing and 30th:15th ratios were significantly lower in both the diabetic groups $B$ and $C$ than those of group A but these values were semilar in group B and C. Values of correlation of fasting plasma glucose with valsalva ratio, HRV in deep breathing and 30th:15th ratios in standing test in all three groups were not statistically significant. But correlation of duration of diabeties with valsalva ratio was stastically significant but with RHV in deep breathing and 30th:15th ratios were not significant. Conclusion: From this study it may be concluded that there was progressive deterioration of parasympathetic function with increase in duration of diabetes in patients suffering from type 2 diabetes.
\end{abstract}

Key Words: Parasympathetic, Nerve, Diabetes, Neuropathy

J Bangladesh Soc Physiol.2008 Dec;(3):42-49.

For author affiliations, see end of text.

http://www.banglajol.info/index.php/JBSP

\section{Introduction}

D

iabetic neuropathy is a very common

complication of diabetes mellitus and

involves progressive loss of peripheral

nerve affecting somatic as well as the autonomic nervous system ${ }^{1}$. Diabetic autonomic neuropathy (DAN) is among the least recognized and understood complication of diabetes mellitus despite its significant effect on survival and quality of life in people with diabetes $^{2,3}$. Again, cardiac autonomic neuropathy (CAN) is also one of the most overlooked complications of diabetes ${ }^{4}$. DAN manifests first in longer nerves. The vagus the longest nerve of the autonomic nervous system is affected earlier accounted for about $75 \%$ of all parasympathetic activity ${ }^{1}$.

CAN is the clinically important form of DAN and is strongly associated with an increased risk of silent myocardial ischemia and mortality ${ }^{1}$.

J Bangladesh Soc Physiol. 2008 Dec;(3):42-49 
Cardiac vagal damage has been observed in asymptomatic autonomic neuropathic patients 5. 'O' Brein et al ${ }^{6}$ observed $25.40 \%$ mortality rate in asymptomatic diseased subjects where only autonomic nerve function tests were abnormal. CAN can be assessed by cardiovascular reflex tests ${ }^{7}$. San-antonio conference ${ }^{8}$ recommended that cardiovascular reflex tests are non-invasive, validated, reliable and reproducible. Sub clinical autonomic neuropathy can be detected earlier by using cardiac reflex tests. Mackay et al. ${ }^{11}$ used two tests for the diagnosis of diabetic autonomic neuropathy. These are measurement of heart rate variation during deep breathing and heart rate changes on standing up. They found abnormal Heart rate variation (HRV) in 30\% of patients. Gradual increase in heart rate after standing in patients with diabetic autonomic neuropathy was observed ${ }^{12}$. Abnormal HRV in valsalva maneuver was observed in most of the newly diagnosed type 2 diabetic patients ${ }^{13-16}$. On the contrary, Dyrberg et al. ${ }^{17}$ also studied autonomic nerve function in type 2 diabetic subjects and found no abnormal subjects in lying to standing test. HRV on deep breathing has proved to be the more sensitive diagnostic index of autonomic neuropathy ${ }^{11}$. Loss of normal HRV due to cardiac autonomic neuropathy probably provides the best and simplest bed side test of autonomic function which has extensively been used ${ }^{18}$.

In Bangladesh, a large number of diabetic patients are suffering from diabetic neuropathy. Among them a quiet large number may have diabetic cardiac autonomic neuropathy which remains undetected unless complicated. Cardiac parasympathetic neuropathy is the clinically important form of diabetic autonomic neuropathy. Therefore, the present work has been designed to observe the cardiac parasympathetic nerve function parameters in type 2 diabetic patients and in non diabetic healthy subjects for comparison and also for a base line data to elucidate a set of reference values of parasympathetic nerve function parameters in adult Bangladeshi population. At the same time this study may be helpful to explore the role of glycemic control and duration of diabetes in type 2 diabetes mellitus.

\section{Methods}

In this present work, 47 type w diabetic patints 40 to 68 type 2 diabetic were taken age study group and subdivided into two groups. Group B consisted of 25 recently diagnosed diabetic subjects and group C consisted of 22 subjects having diabetes for $10-20$ years. 25 age and BMI matched healthy subjects were included in group A (non - diabetic) for control. Diabetic subjects were selected from the Out-Patient Department (OPD) of BIRDEM, Dhaka. Healthy controls were selected from the friends and relatives of the investigator and also from the friends of the patients. None of them had history of diabetes up to second degree relation. The tests to be performed were explained to individual subjects before blood sample collection and then written informed consents were taken from them. On the day of examination, fasting blood samples were collected in the morning after 10-16 hours of overnight fast and then their parasympathetic nerve function tests were done on the same day. No food, coffee, tea or nicotine were permitted 3 hours before the study. Estimation of all the biochemical test i.e. glycated hemoglobin $\left(\mathrm{HbA}_{1 \mathrm{c}}\right)$, fasting plasma glucose (FPG), serum creatinine were done in the Biomedical Research Group Laboratory, BIRDEM and parasympathetic nerve function tests were measured in the Neurophysiological Laboratory of the Physiology Department, BSMMU, Dhaka. 
Article

With all aseptic precautions $4 \mathrm{ml}$ of venous blood was drawn from the antecubital vein with a sterilized plastic disposable syringe. After collection of blood sample $2 \mathrm{ml}$ of whole blood was taken immediately in a test tube containing EDTA anticoagulant for estimation of $\mathrm{HbA}_{1 \mathrm{c}}$. Rest of the blood sample was centrifuged by 3000 RPM for 15 minutes and separated serum was immediately preserved at- $70^{\circ} \mathrm{C}$ for estimation of serum levels of FPG \& creatinine. The body weight in kilogram (kg) was measured in patient with light clothing and height in centimeters $(\mathrm{cm})$ by using appropriate scales on bare foot (Detect-Medic, Detect Scales INC, USA). BMI of the subjects were calculated from the measured weight and height. Serum glucose was estimated by glucose oxidase (GOD/PAP) method (Bio-labo France). Percentage of glycosylated hemoglobin $\left(\mathrm{HbA}_{1 \mathrm{c}}\right)$ was measured in whole blood by a Variant ${ }^{\text {tm }}$ II hemoglobin $\mathrm{A}_{1 \mathrm{c}}$ program testing system (Bio-Rad model) using a modified HPLC method. Serum
Parasympathetic functions in type 2 diabetes

creatinine was measured by Alkaline picrate method (Randox Laboratories, UK). Parasympathetic functions were assessed by three simple cardiovascular reflex tests ${ }^{19}$. These tests can be preformed easily with minimal equipments. Instruments needed are sphygmomanometer, an ECG machine, a mercury column attached to a mouthpiece by a rigid flexible tube.

Data were expressed as mean $\pm \mathrm{SD}$ and range. To compare among groups one way ANOVA with Bonferroni t test was performed as the test of significance. The Pearson's correlation coefficient were done to observe relationship among different variables.

\section{Results}

The mean ( $+\underline{S D})$ age and BMI of the study groups are shown in table 1 . No statistically significant differences of age and BMI were observed among differeznt study groups, therefore all the groups were matched for age and BMI.

Table - I: Mean \pm SD in different groups Age and BMI $(\mathrm{N}=72)$

\begin{tabular}{lccc}
\hline Groups & $\mathrm{N}$ & Age (years) & BMI $(\mathrm{kg} / \mathrm{m} 2)$ \\
\hline A & 25 & $51.92 \pm 5.64$ & $25.28 \pm 2.98$ \\
& & $(45.00-67.00)$ & $(19.56-31.40)$ \\
B & 25 & $51.52 \pm 6.93$ & $24.58 \pm 2.48$ \\
& & $(40.00-68.00)$ & $(18.29-28.35)$ \\
C & $55.77 \pm 5.81$ & $24.57 \pm 2.76$ \\
& 22 & $(45.00-68.00)$ & $(19.70-30.45)$ \\
\hline Statistical Analysis & & \\
\hline Groups & & $>0.50^{\mathrm{NS}}$ \\
A vs. B & $>0.50^{\mathrm{NS}}$ & $>0.50^{\mathrm{NS}}$ \\
A vs. C & $>0.10^{\mathrm{NS}}$ & $>0.50^{\mathrm{NS}}$ \\
B vs. C & $>0.05^{\mathrm{NS}}$ &
\end{tabular}

Values in parenthesis indicate ranges

NS $=$ Not significant

Group A = Control (healthy non-diabetic)

Group B = Recently diagnosed diabetes.

Group C $=$ Diabetes mellitus for $10-20$ years 
Glycemic status are shown in the table 2 . Glycemic status among the control and diabetic groups differed significantly. FPG levels and percentage of $\mathrm{HbA}_{\mathrm{lc}}$ significantly higher in both the diabetic groups $\mathrm{B}(\mathrm{P}<0.001)$ and $\mathrm{C}(\mathrm{P}<0.001)$ in comparison to those of control group $\mathrm{A}$. However, no significant differences these values were observed between the diabetic groups $B$ and $\mathrm{C}(\mathrm{P}>0.50)$.

Parasympathetic nerve function parameters in different study groups are shown in table III. Valsalva ratio was significantly lower in diabetic group C compared to that of control group A $(\mathrm{P}<0.001)$. No significant lower ratio was observed in diabetic group B compared to that of control group $\mathrm{A}(\mathrm{P}>0.10)$ and also in between two diabetic group $\mathrm{B}$ and $\mathrm{C}(\mathrm{P}>0.05)$. HRV was significantly lower in both the diabetic groups $\mathrm{B}$ $(\mathrm{P}<0.001)$ and $\mathrm{C}(\mathrm{P}<0.001)$ compared to that of group A. Again, this HRV was lower in group $\mathrm{C}$ than that of group B but the difference was not statistically significant. In heart rate response to standing test $30^{\text {th }}: 15^{\text {th }}$ ratio were significantly lower in both diabetic group $\mathrm{B}(\mathrm{P}<0.05)$ and $\mathrm{C}$ $(\mathrm{P}<0.001)$ compared to that of control group A. No such lower ratio was observed in between diabetic group $\mathrm{B}$ and $\mathrm{C}(\mathrm{P}>0.50)$.

Relationship of parasympathetic nerve function parameters with FPG status in different study groups were shown in table IV. Valsalva ratio was negatively correlated with FPG in group A and $\mathrm{C}$ and was positively correlated in group $\mathrm{B}$. None of the correlations were statistically significant. HRV were positively correlated with FPG in group A and B and was negatively correlated in group C. None of the correlations were statistically significant. 30th:15th ratio was negatively correlated with FPG in all the groups. None of the correlations were statistically significant.

Relationship of parasympathetic nerve function parameters with $\mathrm{HbA}_{1 \mathrm{c}}$ status in different study groups were shown in table V. Valsalva ratio

Table - II: Glycemic status in different study groups ( $\mathrm{N}=72$ )

\begin{tabular}{llcc}
\hline Groups & $\mathrm{N}$ & $\mathrm{FPG}(\mathrm{mmol} / \mathrm{L})$ & $\mathrm{HbA}_{\mathrm{lc}} \%$ \\
\hline A & 25 & $4.79 \pm 0.74(3.50-6.30)$ & $5.36 \pm 0.37(4.50-5.90)$ \\
B & 25 & $9.27 \pm 2.27(7.09-14.10)$ & $8.04 \pm 1.57(5.40-10.00)$ \\
C & 22 & $9.31 \pm 2.46(4.75-15.30)$ & $8.37 \pm 1.39(5.90-10.60)$ \\
\hline
\end{tabular}

Statistical Analysis

\begin{tabular}{lcc}
\hline Groups & P value & P value \\
\hline A vs. B & $<0.001$ & $<0.001$ \\
A vs. C & $<0.001$ & $<0.001$ \\
B vs. C & $>0.05^{\mathrm{NS}}$ & $>0.05^{\mathrm{NS}}$ \\
\hline
\end{tabular}

\begin{tabular}{ll}
\hline $\mathrm{N}$ & $=$ Total number of subjects. Values in parenthesis indicate ranges \\
$*$ & $=$ Significant \\
$\mathrm{NS}$ & $=$ Not significant \\
Group A & $=$ Control (healthy non-diabetic) \\
Group B & $=$ Recently diagnosed type- 2 diabetes mellitus. \\
Group C & $=$ Type-2 diabetes mellitus for $10-20$ years
\end{tabular}

J Bangladesh Soc Physiol. 2008 Dec;(3):42-49 
Article

Parasympathetic functions in type 2 diabetes

Table - III: Parasympathetic nerve function parameters in different study groups ( $\mathrm{N}=72$ )

\begin{tabular}{lcccc}
\hline Groups & $\mathrm{N}$ & $\begin{array}{c}\text { Valsalva } \\
\text { ratio }\end{array}$ & $\begin{array}{c}\text { HRV in deep } \\
\text { breathing test } \\
\text { (beats/min) }\end{array}$ & $\begin{array}{c}\text { HRV after } \\
\text { standing } \\
\left(30^{\text {th }}: 15^{\text {th }}\right.\end{array}$ \\
\hline A & 25 & $1.41 \pm 0.20$ & $17.68 \pm 3.48$ & $1.11 \pm 0.05$ \\
& & $(1.21-1.92)$ & $(11.00-24.00)$ & $(1.05-1.22)$ \\
B & 25 & $1.32 \pm 0.23$ & $11.68 \pm 4.43$ & $1.04 \pm 0.09$ \\
& & $(1.02-1.76)$ & $(6.00-20.00)$ & $(0.83-1.16)$ \\
C & 22 & $1.19 \pm 0.15$ & $9.41 \pm 4.04$ & $1.01 \pm 0.11$ \\
& & $(1.00-1.42)$ & $(4.00-16.00)$ & $(0.76-1.17)$ \\
\hline
\end{tabular}

Statistical Analysis

\begin{tabular}{llll}
\hline Groups & P value & P value & P value \\
\hline A vs. B & $>0.10^{\mathrm{NS}}$ & $<0.001^{* * *}$ & $<0.05^{*}$ \\
A vs. C & $<0.001^{* * *}$ & $<0.001^{* * *}$ & $<0.001^{* * *}$ \\
B vs. C & $>0.05^{\mathrm{NS}}$ & $>0.10^{\mathrm{NS}}$ & $>0.50^{\mathrm{NS}}$ \\
\hline
\end{tabular}

$\mathrm{N}=$ Total number of subjects. Values in parenthesis indicate ranges

* $\quad=$ Significant

NS $\quad=$ Not significant

Group A $\quad=$ Control (healthy non-diabetic)

Group B = Recently diagnosed type-2 diabetes mellitus.

Group C $\quad=$ Type- 2 diabetes mellitus for $10-20$ years

was negatively correlated with $\mathrm{HbA}_{1 \mathrm{c}}$ in group $\mathrm{A}$ and $\mathrm{C}$ and positively correlated in group $\mathrm{B}$. None of the correlation was statistically significant. HRV was positively correlated with $\mathrm{HbA}_{1 \mathrm{c}}$ in group $\mathrm{B}$ and $\mathrm{C}$ and negatively correlated in group. $30^{\text {th }}: 15^{\text {th }}$ heart rate ratio was negatively correlated with $\mathrm{HbA}_{1 \mathrm{c}}$ in group $\mathrm{B}$ and $\mathrm{C}$ and positively correlated in group $\mathrm{A}$. None of the correlation was statistically significant. Relationship of parasympathetic nerve function parameters with duration of diabetes in group $\mathrm{C}$ were shown in figure 1,2 and 3. Valsalva ratio $(r=-0.950)$, HRV in deep breathing test $(r=-0.258)$ and HRV in standing test was negatively correlated $(r=-0.317)$ with duration of diabetes. Correlation valsalva ratio with duration of diabetes was found statistically significant $(\mathrm{P}<0.001)$. But correlation of HRV in deep breathing test and 30th:15th ratios in standing test duration of diabetes were not statistically significant $(\mathrm{P}>0.05)$.
Table - IV: Relationships of parasympathetic nerve function parameters with FPG in different study groups ( $\mathrm{N}=72$ )

\begin{tabular}{|c|c|c|c|}
\hline Parameters & $\mathrm{N}$ & r value & P value \\
\hline \multicolumn{4}{|c|}{ Valsalva ratio } \\
\hline Group A & 25 & -0.433 & $>0.01^{\mathrm{NS}}$ \\
\hline Group B & 25 & +0.189 & $>0.10^{\mathrm{NS}}$ \\
\hline Group C & 22 & -0.083 & $>0.50^{\mathrm{NS}}$ \\
\hline \multicolumn{4}{|c|}{ HRV in deep breathing test } \\
\hline Group A & 25 & +0.102 & $>0.50^{\mathrm{NS}}$ \\
\hline Group B & 25 & +0.363 & $>0.05^{\mathrm{NS}}$ \\
\hline Group C & 22 & -0.027 & $>0.50^{\mathrm{NS}}$ \\
\hline \multicolumn{4}{|c|}{$30^{\text {th }}: 15^{\text {th }}$ ratio } \\
\hline Group A & 25 & -0.116 & $>0.50^{\mathrm{NS}}$ \\
\hline Group B & 25 & -0.377 & $>0.05^{\mathrm{NS}}$ \\
\hline Group C & 22 & -0.535 & $>0.01^{\mathrm{NS}}$ \\
\hline
\end{tabular}

$\mathrm{N}=$ Total number of subjects.

$+\quad=$ Positive

Group A = Control (healthy non-diabetic)

Group B = Recently diagnosed type-2 diabetes mellitus.

Group C = Type-2 diabetes mellitus for 10 - 20 years

J Bangladesh Soc Physiol. 2008 Dec;(3):42-49 
Parasympathetic functions in type 2 diabetes

Table-V: Relationships of parasympathetic autonomic nerve function parameters with $\mathrm{HbA}_{1} \mathrm{C}$ in different study groups $(\mathrm{N}=72)$

\begin{tabular}{lccc}
\hline Parameters & $\mathrm{N}$ & $\mathrm{r}$ value & P value \\
\hline Valsalva ratio & & & \\
Group A & 25 & -0.199 & $>0.10^{\mathrm{NS}}$ \\
Group B & 25 & +0.143 & $>0.10^{\mathrm{NS}}$ \\
Group C & 22 & -0.064 & $>0.50^{\mathrm{NS}}$ \\
HRV in deep breathing test & \\
Group A & 25 & -0.033 & $>0.50^{\mathrm{NS}}$ \\
Group B & 25 & +0.336 & $>0.10^{\mathrm{NS}}$ \\
Group C & 22 & +0.077 & $>0.50^{\mathrm{NS}}$ \\
30 & & \\
Group A & 25 & +0.061 & $>0.50^{\text {th }}$ ratio \\
Group B & 25 & -0.147 & $>0.10^{\mathrm{NS}}$ \\
Group C & 22 & -0.132 & $>0.50^{\mathrm{NS}}$ \\
\hline
\end{tabular}

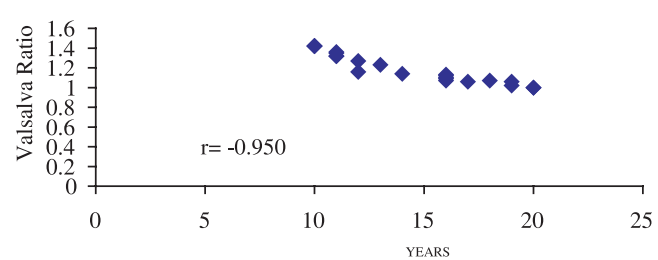

Figure 1. Showing Relationship between Valsalva ratio with duration (Years)

J Bangladesh Soc Physiol. 2008 Dec;(3):42-49
Article

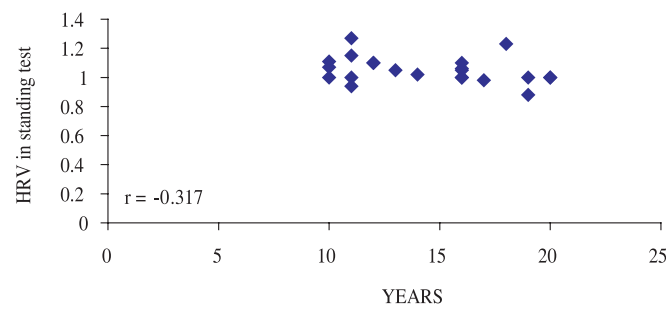

Figure 2. Showing Relationship between HRV in deep breathing test with duration (Years)

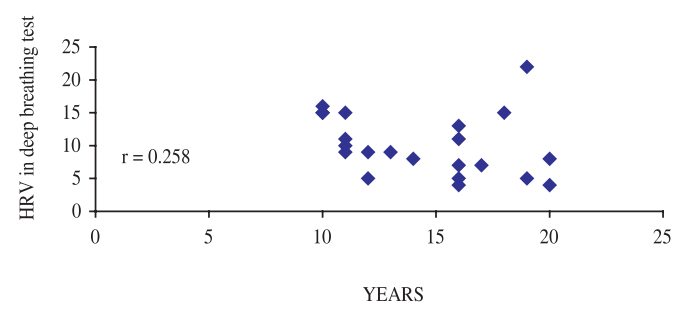

Figure 3. Showing Relationship between HRV after standing with duration (Years)

\section{Discussion}

In the present study all the parameters in non diabetic control are almost similar to those reported by other countries. ${ }^{11,20,17,11,21}$ The glycemic statuses of both the diabetic groups were similar and were also fairly controlled. Fasting plasma glucose and $\mathrm{HbA}_{1 \mathrm{c}}$ levels were significantly higher in recently diagnosed $(\mathrm{P}<0.001)$ and long duration diabetic subjects $(\mathrm{P}<0.001)$ compared to those of healthy subjects. No such significantly higher levels of these values were observed between the two diabetic groups $(\mathrm{P}>0.50)$.

In valsalva maneuver, ratio was found to be significantly reduced in diabetic group of long duration $(\mathrm{P}<0.001)$ compared to that of non diabetic control group. The valsalva ratio was also found to be lower in recently diagnosed diabetic group compared to that of healthy nondiabetic control group but differences was not statistically significant. Again, no statistically significant reduction in valsalva ratio was observed in long duration diabetic group 


\section{Article}

compared to that of recently diagnosed diabetes group. Rahman ${ }^{22}$ also reported a lower value of valsalva ratio in recently diagnosed diabetic group compared to that of non diabetic control group. Similar observation was also reported by Viswanathan et al. ${ }^{20}$, Dyrbeng et al. ${ }^{17}$ in long duration diabetic subjects. In deep breathing test, HRV was found to be significantly reduced in recently diagnosed diabetic group and also in long duration diabetic group compared to that of the non diabetic group. Again, HRV was found to be reduced in long duration diabetic group compared to that of recently diagnosed diabetic group but the difference was not statistically significant. Similar reduction in HRV was also reported in longer duration of diabetes by Rahman ${ }^{21}$; Viswanathan et al. ${ }^{20}$; Dyrbeng et al. $(1981)^{16}$; Mackay et al. (1980) ${ }^{10}$. Rahman ${ }^{21}$ also observed lower HRV in recently diagnosed diabetic patients. In heart rate response to standing, $30^{\text {th }}: 15^{\text {th }}$ ratio was significantly lower in recently diagnosed diabetic group and long duration diabetic group in comparison to healthy non diabetic group. Viswanathan et al. ${ }^{21}$ also made similar observation in long duration diabetes while Dyrberg et al. ${ }^{17}$ and Mackay et al. ${ }^{11}$ in recently diagnosed diabetic subjects.

In the present study, Pearson's correlation of FPG and $\mathrm{HbA}_{1 \mathrm{c}}$ with parasympathetic nerve function parameters were observed and no significant correlations were found. Correlation of duration of diabetes with parasympathetic nerve function parameters were also observed. Decreased heart rate responses to valsalva maneuver in long term diabetes were observed in comparison to that of short term diabetes. Dyrberg ${ }^{17}$ and Viswanathan ${ }^{20}$ also observed similar results. Several investigators made various explanation about the autonomic neuropathy in diabetes mellitus ${ }^{2}$. In addition the factors such as metabolic insult to nerve fibers, neurovascular insufficiency, autoimmune damage, neurohomunal growth factor deficiency are responsible to diabetic autonomic neuropathy ${ }^{23}$ Mclaren et al. ${ }^{24}$ suggested that racial, nutritional and biochemical variations might play significant role in diabetic nerve dysfunction. CAN results from damage to the fibers of the autonomic nervous systems ${ }^{2}$. Hyperglycemia is the major factor which leads to various complications of diabetic patients including neuropathy. Parasympathetic nerve dysfunction occurs in diabetic autonomic neuropathy.

\section{Conclusion:}

Conclusion : From the result of this study it can be concluded that para sympathetic nerve function in type \& diabetes which was related duration of diabetes.

\section{Author Affiliations}

1. * Dr Md Khairul Alam, MBBS, M Phil, Assistant Professor and Head of Physiology, Ibn Sina Medical College, Dhaka, Bangladesh

2. Professor Noorzahan Begum, MBBS, M Phil, FACP (USA), Chairman, Department of Physiology, Bangabandhu Sheikh Mujib Medical University, Dhaka - 1000, Bangladesh

3. Dr Selina Begum, MBBS, M Phil, Associate Professor, Department of Physiology, Bangabandhu Sheikh Mujib Medical University, Dhaka - 1000, Bangladesh

* For correspondence

\section{References}

1. Vinik AI, Maser RE, Mitchell BD, Roy Freeman. Diabetic Autonomic neuropathy. Diabetes care 2003; 26: 1553-1579.

2. Vinik AI, Freeman R, Erbas T. Diabetic autonomic neuropathy. Seminars in neurology 2003; 23: 365-370.

3. Vinik AI, Erbas T. Recognizing and treating diabetic autonomic neuropathy. Cleve Clin J Med. 2001; 68: 928-944.

4. Maser RE, Lenhard MJ, DeCherney GS. Cardiovascular autonomic neuropathy: The clinical significance of its determination. Endocrinologist 2000;10:27-33

5. Gundersen HJG, Neubaur B. A long term diabetic autonomic nervous abnormality: Reduced, variations in resting heart rate measured by simple and sensitive method. Diabetologia. 1977; 13:137-140.

6. O` Brien IA, Lewin IG, O’ Hare JP et al. Abnormal circadian rhythm of melatonin in diabetic autonomic neuropathy. Clin Endocrinol. 1968; 24:356-364.

7. Ewing DJ, Campbell IW, Clark BF. Assessment of cardiovascular effects in diabetic autonomic neuropathy and prognostic implications. Ann Intern Med 1980; 92: 308-311.

J Bangladesh Soc Physiol. 2008 Dec;(3):42-49 
8. San-Antonio conference. Report and recommendations of the San-Antonio conference on diabetic neuropathy. Diabetes 1988; 37 ; 1000 - 1005.

9. Sharpey-Schafer EP, Taylor PJ. Absent circulatory reflexes in diabetic neuritis. Lancet 1960; 1:559-562.

10. Ziegler D. Diabetic cardiovascular autonomic neuropathy: Prognosis, diagnosis and treatment. Diabetes Metab Rev. 1994; 10: 339-383.

11. Mackay JD, Page MM, Cambridge J, Watkins P.J. Diabetic autonomic neuropathy: The diagnostic value of heart rate monitoring. Diabetologia 1980; 18: 471478.

12. Ewing DJ, Cardiovascular reflexes and autonomic neuropathy. Clin sci Mol Med. 1978; 55: 312-7.

13. Xueli Z, Baidi Z, Guoxian H, Xixing Z. Peripheral and autonomic nerve function tests in early diagnosis of diabetic neuropathy. Chiness J Med. 1981; 94: 495502.

14. Morley JE, Asvat MS, Klein C, Lowenthal MN. Autonomic neuropathy in black diabetic patients. S Afr Med J. 1977; 52: 115-116.

15. Hilsted J, Jensen SB. A simple test for autonomic neuropathy in Juvenile diabetes. Acta Med Scand. 1979; 205:385-387.

16. Hulper B, Willms B. Investigations of autonomic diabetic neuropathy of the cardiovascular system. Horm Metab Res. 1980; 9: 77-80.

17. Dyrberg T, Benn J, Christiansen JS, Hilsted, Nerup J. Prevalence of diabetic autonomic neuropathy measured by simple bed side tests. Diabetologia. 1981; 20: 190194.

18. Bennett TM, Farquhar IK, Hosking DJ et al. Assessment of methods for estimating autonomic nervous control of the heart in patient with diabetic mellitus. Diabetes 1978; 27: 1167-75.

19. Bannister R, Mathias CJ. Investigation of autonomic disorder. In: A text book of clinical disorders of the autonomic nervous system. $3^{\text {rd }}$ ed. United Status: Oxford University Press; 1992. p 255-289.

20. Viswanathan V, Prasad D, Chamukuttan et al. High prevalence and early onset of cardiac autonomic neuropathy among south Indian type 2 diabetic patients with nephropathy. Diabetic Research and Clinical Practice. 2000; (48): 211-216.

21. Ewing DJ, Martyn CN, Young RJ, Clarke BF. The value of cardiovascular autonomic function tests: 10 years experience in diabetes. Diabetes Care 1985; 8: 419-498.

22. Rahman HZ. Autonomic Neuropathy in relation to glycemic status, C-peptide level and microtransferrinuria in MRDM. (Thesis). Dhaka university: Institute of post-graduate medicine and research 1996. p 29-62.

23. Vinik AI, Erbas T, Stansberry K. Gastrointestinal, genitourinary and neurovascular disturbances in diabetes. Diabetes Review. 1999; 7:318-378.

24. Mclaren EH, Burden AC, Moorhead PJ. Acetylator phenotype in diabetic neuropathy. Br Med J. 1992; 2: 291-293. 